\title{
MASERS IN SGR B2: SITES OF STAR-FORMING REGIONS
}

\author{
J.B. Whiteoak, F.F. Gardner \& J.R. Forster \\ Division of Radiophysics, CSIRO \\ PO Box 76 Epping NSW 2121 Australia \\ P. Palmer \\ University of Chicago, USA \\ V. Pankonin \\ National Science Foundation Washington USA
}

\begin{abstract}
H}_{2} \mathrm{CO}$ and $\mathrm{OH}$ masers in the HII-region/molecular-cloud complex Sgr B2 have been observed with the VLA and combined with other observations of $\mathrm{OH}$ and $\mathrm{H}_{2} \mathrm{O}$ masers. It is found that groups of the masers and compact continuum components are located along a north-south line extending across the complex. The overall alignment suggests that star formation is being triggered by a single large-scale event such as an interaction between molecular clouds.
\end{abstract}

Many molecular spectral lines have been detected in the dense gas clouds associated with the HII region Sgr B2 (G0.7-0.0). Of particular interest are the maser lines which pinpoint locations where stars are currently forming or are about to form. The presence of $\mathrm{H}_{2} \mathrm{O}$ and $\mathrm{OH}$ masers has been known for some time (e.g. Waak and Mayer 1974; Genzel et al. 1976). More recently Whiteoak and Gardner (1983) detected $\mathrm{H}_{2} \mathrm{CO}$ masers in the complex. This was unexpected - such maser emission has been observed in only one other object (NGC 7538: Downes and Wilson 1974). The preliminary results suggested a large-scale alignment in maser locations.

We have used the Very Large Array* extensively to investigate the molecular clouds of Sgr B2. Some of the results provide further insight into the nature of the maser emission. These concern $\mathrm{H}_{2} \mathrm{CO}$ masers associated with the $4.8 \mathrm{GHz} 1_{10}-1_{11}$ transition, and $\mathrm{OH}$ masers at 1612 and $1720 \mathrm{MHz}\left({ }^{2} \pi_{3 / 2}, \mathrm{~J}=3 / 2\right.$ ground-state transitions) and at 4660 and $4675 \mathrm{MHz}\left({ }^{2} \pi_{1} / 2, \mathrm{~J}=1 / 2\right.$ excited state transitions).

The VLA results are listed in Table 1 , along with the most recent information about the ground-state $\mathrm{OH}$ masers at 1665 and $1667 \mathrm{MHz}$ and the $\mathrm{H}_{2} \mathrm{O}$ masers at $22 \mathrm{GHz}$. The entries are grouped according to position. It can be seen that there are seven general locations; with only one exception (a single $1612 \mathrm{MHz}$ maser) the maser locations are along a well-defined north-south line. Apart from group 7, which includes an $\mathrm{H}_{2} \mathrm{O}$ maser with a poorly-defined position, the individual maser centres agree to within a few arcsecs. Several compact HII regions are disposed

\footnotetext{
*Operated by Associated Universities Inc., under contract with the National Science Foundation.
} 
TABLE 1. MASER POSITIONS AND VELOCITIES IN SGR B2

\begin{tabular}{|c|c|c|c|c|c|c|c|}
\hline \multirow[t]{2}{*}{ Group } & \multirow[t]{2}{*}{ Molecule } & \multicolumn{3}{|c|}{ R.A. (1950) } & Dec. $(1950)$ & \multirow{2}{*}{$\begin{array}{c}\text { Radial } \\
\text { velocity } \\
(\mathrm{km} \mathrm{s}-1)\end{array}$} & \multirow[t]{2}{*}{$\operatorname{Ref}$. } \\
\hline & & $\mathrm{h}$ & m & $s \quad s$ & ० , " " & & \\
\hline 1 & $\begin{array}{l}\mathrm{H}_{2} \mathrm{CO} \\
\mathrm{H}_{2} \mathrm{O}\end{array}$ & $\begin{array}{l}17 \\
17\end{array}$ & $\begin{array}{l}44 \\
44\end{array}$ & $\begin{array}{l}10.08 \pm 0.02 \\
10.03 \pm 0.08\end{array}$ & $\begin{array}{lll}-28 & 21 & 10.8 \pm 0.15 \\
-28 & 21 & 16.3 \pm 1\end{array}$ & $\begin{array}{l}75 \\
20-70\end{array}$ & 1 \\
\hline 2 & $\begin{array}{l}\mathrm{H}_{2} \mathrm{CO} \\
\mathrm{OH}(1665,7)\end{array}$ & $\begin{array}{l}17 \\
17\end{array}$ & $\begin{array}{l}44 \\
44\end{array}$ & $\begin{array}{l}10.26 \pm 0.02 \\
10.22 \pm 0.02\end{array}$ & $\begin{array}{lll}-28 & 21 & 38.9 \pm 0.15 \\
-28 & 21 & 38.3 \pm 0.5\end{array}$ & $\begin{array}{l}52 \\
45\end{array}$ & 2 \\
\hline 3 & $\begin{array}{l}\mathrm{H}_{2} \mathrm{CO} \\
\mathrm{OH}(1612) \\
\mathrm{OH}(1665,7) \\
\mathrm{OH}(4660) \\
\mathrm{H}_{2} \mathrm{O}\end{array}$ & $\begin{array}{l}17 \\
17 \\
17 \\
17 \\
17\end{array}$ & $\begin{array}{l}44 \\
44 \\
44 \\
44 \\
44\end{array}$ & $\begin{array}{l}10.35 \pm 0.02 \\
10.33 \pm 0.02 \\
10.31 \pm 0.03 \\
10.35 \pm 0.02 \\
10.18 \pm 0.08\end{array}$ & $\begin{array}{lll}-28 & 22 & 02.2 \pm 0.15 \\
-28 & 22 & 02.1 \pm 0.1 \\
-28 & 22 & 02.5 \pm 0.3 \\
-28 & 22 & 03.1 \pm 0.5 \\
-28 & 22 & 00.9 \pm 1\end{array}$ & $\begin{array}{l}47,52,(73) \\
61 \\
48-62 \\
60,66 \\
55-81\end{array}$ & $\begin{array}{l}3 \\
4\end{array}$ \\
\hline 4 & $\begin{array}{l}\mathrm{OH}(1720) \\
\mathrm{OH}(4765)\end{array}$ & $\begin{array}{l}17 \\
17\end{array}$ & $\begin{array}{l}44 \\
44\end{array}$ & $\begin{array}{l}10.24 \pm 0.01 \\
10.20 \pm 0.01\end{array}$ & $\begin{array}{lll}-28 & 22 & 10.3 \pm 0.1 \\
-28 & 22 & 10.4 \pm 0.1\end{array}$ & $\begin{array}{l}62 \\
61\end{array}$ & \\
\hline 5 & $\mathrm{OH}(1612)$ & 17 & 44 & $15.61 \pm 0.01$ & $\begin{array}{lll}-28 & 22 & 34.1 \pm 0.1\end{array}$ & 68 & \\
\hline 6 & $\begin{array}{l}\mathrm{H}_{2} \mathrm{CO} \\
\mathrm{OH}(1612) \\
\mathrm{OH}(1665,7) \\
\mathrm{H}_{2} \mathrm{O}\end{array}$ & $\begin{array}{l}17 \\
17 \\
17 \\
17\end{array}$ & $\begin{array}{l}44 \\
44 \\
44 \\
44\end{array}$ & $\begin{array}{l}10.22 \pm 0.02 \\
10.69 \pm 0.02 \\
10.58 \pm 0.01 \\
10.42 \pm 0.08\end{array}$ & $\begin{array}{lll}-28 & 22 & 44.3 \pm 0.15 \\
-28 & 22 & 43.3 \pm 0.2 \\
-28 & 22 & 42.2 \pm 0.4 \\
-28 & 22 & 44.5 \pm 1\end{array}$ & $\begin{array}{l}48,50,54 \\
75 \\
67-71 \\
59-72\end{array}$ & $\begin{array}{l}3 \\
4\end{array}$ \\
\hline 7 & $\begin{array}{l}\mathrm{H}_{2} \mathrm{CO} \\
\mathrm{H}_{2} \mathrm{O}\end{array}$ & $\begin{array}{l}17 \\
17\end{array}$ & $\begin{array}{l}44 \\
44\end{array}$ & $\begin{array}{l}08.79 \pm 0.02 \\
09.7 \pm 0.8\end{array}$ & $\begin{array}{llll}-28 & 23 & 22.2 \pm 0.15 \\
-28 & 23 & 10 \pm 15\end{array}$ & $\begin{array}{l}49,52 \\
57-71\end{array}$ & 5 \\
\hline
\end{tabular}

along the same north-south line (see e.g. Benson and Johnston 1984), and three coincide with maser groups.

The large-scale order suggests that present star formation in the Sgr B2 region is being controlled by a single mechanism. This might be an interaction between the outer edge of a large molecular cloud associated with Sgr B2 and the surrounding interstellar medium, resulting in instabilities leading to star foramtion. The large spread in velocity within each maser grouping may be caused by velocity gradients in conjunction with different maser positions for the different molecules.

The pairing of 1612 and $4660 \mathrm{MHz}$ masers, and of 1720 and $4765 \mathrm{MHz}$ masers, seems significant. The latter also occurs in NGC 7538 but lacks a simple interpretation (Palmer et al. 1985). Preferential $1720 \mathrm{MHz}$ emission may be due to a high $\mathrm{H}_{2}$ density and collisional excitation in the presence of radiative pumping that produces the $4765 \mathrm{MHz}$ emission. REFERENCES

Benson, J.M., and Johnston, K.J.: 1984, Astrophys. J. 277, L181. Downes, D., and Wilson, T.L.: 1974, Astrophys. J. 191, L77.

Elmegreen, B.G., Genzel, R., Moran, J.M., Reid, M.J., and Walker, R.C.: 1980, Astrophys. J. 241, 1007.

Frrster, J.R., Welch, W.J., Wright, M.C.H., and Baudry, A.: 1978, Astrophys. J. 221, 137.

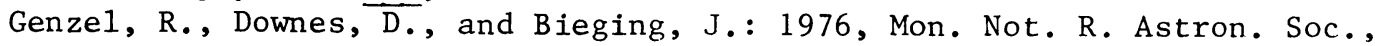
$117,101 \mathrm{P}$. 
Palmer, P., Gardner, F.F., and Whiteoak, J.B.: 1984, Mon. Not. R. Astron. Soc. $211,41 \mathrm{P}$.

Waak, J.A., and Mayer, C.H.: 1974, Astrophys. J. 189, 67.

Whiteoak, J.B., and Gardner, F.F.: 1.983, Mon. Not. R. Astron. Soc. 205, $27 \mathrm{P}$.

CLUMPY STRUCTURE IN THE W3 MOLECULAR CORE

Hideyuki Kobayashi, Masahiko Hayashi

Department of Astronomy, University of Tokyo, Japan

Tetsuo Hasegawa

Nobeyama Radio Observatory, University of Tokyo, Japan

The core region of the W3 molecular cloud has high molecular line luminosities (Dickel et al. 1980; Brackman and Scoville 1980). This region contains luminous infrared sources and ultra compact H II regions. A young star cluster may be forming in this region. Recent interferometric high angular-resolution observation revealed a bipolar outflow toward IRS 5 in the CO emission (Claussen et al. 1984) and a mass condensation in the HCN emission (Wright et al. 1984) in this region.

We have carried out a CO $(\mathrm{J}=1-0)$ and a $\operatorname{CS}(\mathrm{J}=1-0)$ mapping in the $2^{\prime} \times 2^{\prime}$ area of the W3 core using the Nobeyama 45-m telescope. The angular and velocity resolutions are $15^{\prime \prime}$ and $0.65 \mathrm{~km} \mathrm{~s}^{-1}$ for the CO observations, and $33^{\prime \prime}$ and $0: 2 \mathrm{~km} \mathrm{~s}^{-1}$ for the CS observations, respectively. The field of our observations is larger than those of previous interferometric observations. We can see the overall structure of a young star cluster with high angular-resolution.

Our main results are:

1. The CO spectra have a wide variety of velocity components which appear and disappear from point to point. Each of these velocity components corresponds to a localized maximum in the equalvelocity maps (Figure 1). Most of these components do not coincide with known IR sources. These components may form part of a shell around IRS 5-7. The size of the condensations is $<0.1 \mathrm{pc}$. The velocity widths of the components are typically $2 \mathrm{~km} \mathrm{~s}^{-1}$.

2. Some of the CO emission features at blue- and red-shifted velocities around IRS 5 correspond to a bipolar outflow which has been noticed by Claussen et al. (1984) (Figure 2).

3 . There is a steep systematic velocity gradient from the northwest to the southeast of the central infrared cluster IRS 3-7 where the Co profiles are self-reversed. The steepest velocity gradient of $14 \mathrm{~km}$ $\mathrm{s}^{-1} \mathrm{pc}^{-1}$ for the CO emission (Fig. 2) and $11 \mathrm{~km} \mathrm{~s}^{-1} \mathrm{pc}^{-1}$ for the CS emission (Figure $3 \mathrm{~b}$ ) occurs toward the IRS 5-7 position. Although this has been interpreted as a rotation (Brackmann and Scoville 1980), this 